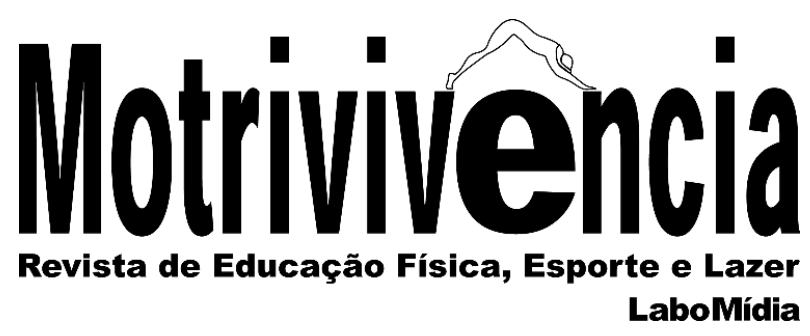

\title{
O atual cenário da formação docente no Brasil: os desdobramentos da BNCC nos cursos de licenciatura
}

\section{RESUMO}

$\mathrm{O}$ presente artigo objetiva entender as implicações das políticas educacionais no contexto atual da formação de professores, em específico na área da Educação Física. Partimos da Base Nacional Comum Curricular (BNCC), dialogando com a Resolução 2/2019, até as repercussões nas novas legislações, gestadas pós BNCC, as quais têm norteado inúmeras políticas socioeducativas, entre elas, a proposta do Programa Residência Pedagógica (PRP). Os resultados, elaborados a partir de leituras de materiais e documentos, apontam que a BNCC propõe a formação docente a partir de competências e habilidades, configuradas em um caráter tecnocrático/tecnicista. Tem-se assim, uma formação muito mais prática, descaracterizada de análises críticas.

PALAVRAS-CHAVE: Políticas educacionais; Base nacional comum curricular; Programa residência pedagógica; Educação física
Michael Flores Milani

Especialista em Educação Física Escolar Universidade Federal de Santa Maria - UFSM, Centro de Educação Física e Desportos, Santa Maria, Brasil michamilani17@gmail.com

https://orcid.org/0000-0002-2375-0969

Gabriel Vielmo Gomes

Especialista em Educação Física Escolar Universidade Federal de Santa Maria - UFSM, Centro de Educação Física e Desportos, Santa Maria, Brasil

gabrielvgef@gmail.com

${ }^{(1)}$ https://orcid.org/0000-0002-7428-7855

Maristela da Silva Souza

Doutora em Ciência do Movimento Humano Universidade Federal de Santa Maria - UFSM, Departamento de Desportos Individuais, Brasil maristeladasilvasouza@yahoo.com.br

() https://orcid.org/0000-0002-9624-3060 
The current scenario of teaching training in Brazil: the developments of BNCC in licensing courses

\begin{abstract}
This article aims to understand the implications of educational policies in the current context of teacher training, specifically in the area of Physical Education. We started from the National Common Curricular Base (BNCC), dialoguing with Resolution 2/2019, until the repercussions in the new legislation, created after BNCC, which have guided numerous socio-educational policies, among them, the proposal of the Pedagogical Residency Program (PRP). The results, elaborated from readings of materials and documents, point out that BNCC proposes teacher training based on competences and skills, configured in a technocratic/technicist character. Thus, there is a much more practical training, which is not characterized by critical analyzes.
\end{abstract}

KEYWORDS: Educational policies; Common national curricular base; Pedagogical residence program; Physical education

\title{
El escenario actual de la formación docente en Brasil: los desarrollos del BNCC en los cursos de pregrado
}

\section{RESUMEN}

Este artículo tiene como objetivo comprender las implicaciones de las políticas educativas en el contexto actual de la formación docente, específicamente en el área de Educación Física. Partimos de la Base Curricular Común Nacional (BNCC), dialogando con la Resolución 2/2019, hasta las repercusiones en la nueva legislación, creada después del BNCC, que ha orientado numerosas políticas socioeducativas, entre ellas, la propuesta del Programa de Residencia Pedagógica. (PRP). Los resultados, elaborados a partir de lecturas de materiales y documentos, muestran que BNCC propone una formación docente basada en competencias y habilidades, configuradas en un carácter tecnocrático/tecnicista. Así, hay una formación mucho más práctica, que no se caracteriza por análisis críticos.

PALABRAS-CLAVE: Políticas educativas; Base curricular nacional común; Programa de residencia pedagógica; Educación física 


\section{INTRODUÇÃO}

Nos últimos anos, o contexto educacional foi impactado pela publicação na íntegra, do novo marco regulatório para o desenvolvimento da aprendizagem no ensino básico brasileiro. A Base Nacional Comum Curricular (BNCC), do ponto de vista histórico, inicia-se pela constituição da Comissão Bicameral, criada pela Portaria CNE/CP no 11/2014 (AGUIAR, 2018). A comissão bicameral divulga sua primeira versão da BNCC, ainda em 2015, com objetivo que a sociedade civil (organizações e instituições científicas) pudesse auxiliar na construção do documento. Já no ano de 2016, a segunda versão da BNCC é divulgada, levando em conta as contribuições levantadas, em um primeiro momento. Desta forma, o documento se caracterizava em um processo de construção colaborativa, dialogando com o público da área educacional.

Contudo, posteriormente a divulgação da segunda versão, é efetivada mudança na composição do conselho, em decorrência dos atos sucessivos do presidente Interino Michel Temer e de seu ministro da Educação. É nesse novo contexto, que em 2017 que a terceira versão do documento é entregue ao Conselho Nacional de Educação (CNE) pelo Ministério da Educação (MEC), com a exclusão do ensino médio na redação da normativa. Segundo Aguiar (2018), a nova versão foi construída autonomamente pelo Comitê Gestor, com caráter linear, vertical e centralizador. A integralização da BNCC, foi concretizada a partir da homologação do documento "Base Nacional Comum Curricular para a etapa do Ensino Médio”, em que pela primeira vez a educação básica brasileira passou a contar com a previsão, em todas as suas etapas, das aprendizagens consideradas essenciais e previstas na nova normativa educacional.

Como desdobramentos da nova normativa norteadora da formação básica, a saber, BNCC, foram implementadas, no mesmo período, novas políticas no universo educacional. Primeiramente, o Programa Residência Pedagógica (PRP), publicado pela Coordenação de Aperfeiçoamento de Pessoal de Nível Superior (CAPES) através do edital 6/20181 perspectivando a implementação de projetos inovadores que estimulem articulação entre teoria e prática nos cursos de formação em licenciatura, conduzidos em parceria com as redes públicas de educação básica (CAPES, 2018).

Também relacionada a BNCC, a Resolução 2/2019² sancionada no final de 2019, visa estabelecer as novas Diretrizes Curriculares Nacionais (DCN) para a Formação Inicial de Professores para a Educação Básica e institui a Base Nacional Comum para a Formação Inicial de Professores da Educação Básica (BNC-Formação) (BRASIL, 2020).

\footnotetext{
Edital disponível na integra em: https://www.gov.br/capes/pt-br/centrais-de-conteudo/01032018-edital-6-2018residencia-pedagogica-pdf/view.

${ }^{2}$ Resolução CNE/CP, disponível em: http://portal.mec.gov.br/docman/dezembro-2019-pdf/135951-rcp002-19/file.
} 
Nessa conjuntura, entendemos a necessidade de identificar as implicações da BNCC na formação de professores de Educação Física. Para tanto, temos como objetivos analisar o imbricamento das novas políticas (PRP e Resolução 2/2019) na formação de professores da educação básica, dando enfoque especial, na formação docente em Educação Física.

Para fins metodológicos nosso estudo estrutura-se a partir de uma pesquisa bibliográfica, sendo desenvolvida com base em materiais já elaborados, constituído de livros e artigos científicos, e ainda se ancora em uma pesquisa documental, a qual propõe analisar os documentos de "primeira mão" (GIL, 2008). Com isso, delineamos dialogar com o conhecimento já existente, que tematizam as implicações ocasionadas pela BNCC no processo de formação em Educação Física, bem como, as repercussões nas novas legislações, gestadas pós BNCC.

\section{A FASE ATUAL DA POLÍTICA EDUCACIONAL NO BRASIL}

Atualmente, a sociedade é definida a partir de ideais capitalistas, onde busca através do desenvolvimento de novas políticas (serviços, regulamentações, mercado) reorientar as ações do Estado no cenário social. Nesse sentido, tais políticas são desenvolvidas a partir das novas necessidades do mundo globalizado, na tentativa de reorganiza-lo, preparando assim, tanto o ambiente como os indivíduos, para o novo quadro sócio-político e econômico do século XXI.

Nesse contexto, Barone (2000) afirma que, desde meados dos anos 70, as proposições políticas, estão identificadas com o ideário neoliberal, implicando em normativas sociais que, alteram a relação entre o público e o privado, o papel do ente estatal na implementação dessas políticas, bem como, na constante problemática do emprego/desemprego inerente ao modo de produção capitalista. Tendo isso em mente, tais temáticas têm tido destaque nas proposições feitas por agências/organismos internacionais na elaboração da agenda de diferentes setores da sociedade, sobretudo nos países dito em desenvolvimento.

A partir disso, e nesse meio, entre os diferentes setores, "a política passou a designar um campo dedicado ao estudo da esfera de atividades humanas articulada às coisas do Estado e que o conjunto de atividades, que, de alguma maneira, são atribuídas a ele ou que dele emanam" (SHIROMA; MORAES; EVANGELISTA, 2002, p.7). Tem-se assim, a partir das políticas públicas, a elaboração de princípios/ideias educacionais, as quais visam qualificar a educação/ensino público.

As políticas educacionais estão relacionadas a uma série de metas, ações e planos implementadas por um governo [...] e têm por finalidade intervir nos processos formativos desenvolvidos em sociedade. Constituem-se enquanto elemento de normatização do Estado, pois, cerceiam-se dos diversos conflitos sociais 
manifestados nas disputas políticas. Dado isso, é notável que as políticas públicas educacionais surgem como produto desses embates. [...] Compreendemos que as políticas educacionais tal como as políticas públicas surgem da correlação de forças entre o Estado, os interesses do capital e as demandas da sociedade civil (COSTA; GONÇALVES, 2019, p. 34-35).

Corroborando, Mészáros (2010) define que os processos educacionais estão intimamente ligados aos processos sociais mais abrangentes de reprodução do capital. Nesse sentido, o autor também afirma que sem uma transformação significativa do quadro social, é inadmissível uma reforma expressiva da educação, sendo possível apenas ajustes menores com o objetivo de corrigir algum detalhe da ordem já estabelecida no cenário social, mantendo assim, intactos os princípios estruturais/fundamentais do capitalismo.

Nessa perspectiva, a educação tem sido formatada para busca da maior produtividade, qualidade e competitividade, características da nova economia de mercado crescente na era da globalização. Ou seja, redefini os conceitos, como por exemplo, de espaço e tempo, balizados nas novas tecnologias da microinformática e nas relações sociais mais dinâmicas da contemporaneidade.

Barone (2000) sintetiza que o atual cenário é marcado pelas mudanças do trabalho, da lógica da empregabilidade e da necessidade de o trabalhador estar conectado aos processos de modificações do mercado. Para isso, é necessária a capacidade adaptativa e compreensiva dos novos processos técnico-tecnológicos, necessitando, portanto, saber comunicar-se eficientemente, bem como, adquirir constantemente os novos aprendizados.

A partir dessa leitura, percebe-se que o desenvolvimento de políticas, voltadas ao contexto educacional, consentem numa perspectiva capitalista. Ou seja, a proposição de qualidade dessas políticas, acompanha as demandas imperialistas, reforçando a ideia de criar/formar indivíduos compatíveis a essa lógica reprodutiva do atual sistema socioeconômico. Não isoladas deste cenário, a formação de professores nos cursos de licenciatura, têm sido provocada a constantes alterações no seu caminho curricular, visando formar profissionais moldados a nova dinâmica do mercado de trabalho.

Para isso, têm surgido no contexto educacional, políticas que integram a Política Nacional de Formação de Professores (PNFP), voltadas para a aproximação entre os espaços formadores, e contextos de atuação profissional, como por exemplo, o PIBID, PRP e a Resolução 2/2019. Para tanto, observamos a necessidade de apresentar o conteúdo existente nos editais do PRP e da nova Resolução 2/2019 com a finalidade de demonstrar a relação dessas políticas no recente período. 


\section{O IMBRICAMENTO DO PROGRAMA RESIDÊNCIA PEDAGÓGICA COM AS NOVAS DIRETRIZES CURRICULARES NACIONAIS}

Elencamos, inicialmente, como um dos objetos de análise do presente estudo, o PRP, compreendendo-o esse, a partir da ótica de Mészáros (2010) de reformulações menores e adaptativas no campo educacional e, por consequência, no processo de formação docente, visando readequá-los aos novos mecanismos impostos pelo sistema do capital na contemporaneidade.

Inspirado na Residência Médica, a primeira proposta de programa de residência no ambiente escolar, foi apresentada no ano de dois mil e sete (2007) e, a partir desse período passou por inúmeras discussões e reformulações, até ser implementada através do edital 6/2018. Inicialmente, manifestado pelo PLS 227/07, ponderava a "residência educacional", com carga horária de 800 horas e, previa após dois anos de implementação, a exigência de certificado para o exercício da docência nos anos iniciais. A segunda proposta discutida data de 2012, o Projeto de Lei (PLS) $n^{\circ}$ 284/12, apontou à reformulação do programa, dentre suas mudanças, o projeto propôs como denominação "Residência Pedagógica" sendo remunerada por meio de bolsas de estudos. A terceira tentativa (2014), dada pela PLS 6/2014, sugeriu novas mudanças, passando a ser denominado de "Residência Docente". O referido projeto determinava a residência como uma etapa extra à formação inicial, de 1.600 horas, divididas em dois períodos com duração mínima de 800 horas (SILVA; CRUZ, 2018).

Diferentemente das tentativas não efetivadas de implementar programas de residência no país, ainda no ano de 2007, houve a concretização do Programa Institucional de Bolsas de Iniciação à Docência (PIBID), que objetivava conceder bolsas de iniciação à docência aos estudantes, bem como aos professores das IES ${ }^{3}$, e professores da Educação Básica (EB), visando potencializar a articulação entre a Educação superior, a escola e os sistemas estaduais e municipais de EB. Do ponto de vista quantitativo, em 2012 o programa concedia 49.321 bolsas, passando para 90.254 bolsas no ano de 2014 (PORTELINHA; NEZ; BORDIGNON, 2020).

De acordo com os autores, essa realidade sintetizava um marco regulatório com forte característica de ação estratégica, gestado para enfrentar a questão da melhoria do ensino nas escolas públicas. Entretanto, em advento da crise político-econômica no país, intensificada a partir de 2015, constante ameaças de reestruturação e cortes financeiros foram colocados ao PIBID.

Nesse novo cenário ${ }^{4}$, em 2018 o governo lança dois editais distintos pertinentes à PNFP. O

\footnotetext{
${ }^{3}$ Refere-se à Instituição de Ensino Superior.

${ }^{4}$ Esse período acirra-se com a escalada de Michel Temer ao poder executivo. Para Souza, Bosco e Oliveira (2020), o governo ilegítimo pôs em prática uma política de austeridade que, contando com o auxílio de larga maioria do congresso nacional, aprovou o congelamento de gastos sociais por vinte anos (emenda constitucional 95/2016) e, por conseguinte, a agenda educacional passou a obter restrições/retrocessos em suas políticas e/ou programas.
} 
edital 7/2018 materializa a continuação do PIBID, porém com reformulações nos seus projetos institucionais e o edital 6/2018 que instituiu o PRP. Os mesmos foram marcados por exigências e adequações a critérios quantitativos, desconsiderando a ampliação de bolsas dos programas, provocando assim, uma divisão das mesmas, da qual a sua racionalidade e o forte apelo ao voluntariado e, que já passam a ser criticados pelas entidades de formação de professores (PORTELINHA; NEZ; BORDIGNON, 2020).

Dito isso, o PRP através do edital 6/2018 apresentou como objetivos: o aperfeiçoamento da formação nos cursos de licenciatura, através de projetos que fortaleceram o campo da prática, levando o licenciado a exercitar a relação teoria e prática profissional docente; Induzir a reformulação do Estágio Supervisionado, tendo por base a experiência da residência pedagógica; Ampliar e consolidar a relação entre a IES e o ambiente escolar; Adequar os currículos e propostas pedagógicas dos cursos de formação inicial de professores da educação básica às orientações da BNCC (CAPES, 2018). Na mesma perspectiva, o edital $1 / 2020^{5}$, ao perpetuar os mesmos objetivos elencados no edital anterior, bem como a abrangência do público a ser contemplado ${ }^{6}$ pelo programa, designa, por conseguinte, a conservação dessa política, enquanto uma das ações que integram a atual PNFP.

Em consonância com os objetivos propostos pelo PRP, como também a materialidade da execução de programas que visam a inserção dos alunos das licenciaturas nas redes escolares, que a recente Resolução CNE/CP No 2/20197 vai defender que:

[...] a formação de professores exige um conjunto de conhecimentos, habilidades, valores e atitudes, que estão inerentemente alicerçados na prática, a qual precisa ir muito além do momento de estágio obrigatório, devendo estar presente, desde o início do curso, tanto nos conteúdos educacionais e pedagógicos quanto nos específicos da área do conhecimento a ser ministrado; (BRASIL, 2020, p. 87).

Portanto, a conservação de programas como o PRP e o PIBID, se configura como um elemento "acessório" importante na política de formação docente, possibilitando aos estudantes a sua inserção (prática) no ambiente escolar, para além dos atuais estágios supervisionados, visando o desenvolvimento de habilidades/competências essenciais ao cotidiano escolar. Essas habilidades e competências se pautam como veremos mais adiante, intrinsecamente em consonância com as pautas econômicas.

\footnotetext{
5 Edital disponível na integra em:_ https:/www.gov.br/capes/pt-br/centrais-de-conteudo/06012020-edital-1-2020residencia-pedagogica-pdf/view. Acesso em: 10 set. 2020.

${ }^{6}$ Cada subprojeto será composto: 01 coordenador do subprojeto (professor IES), 03 preceptores (professores de rede pública) e 24 residentes bolsistas e com possibilidade de acréscimo de seis residentes voluntários (acadêmicos de licenciatura). O edital 1/2020 prevê o quantitativo máximo de bolsas a ser disponibilizadas num total de 30.096 cotas da modalidade residente (CAPES, 2020).

7 Disponível em: https://pesquisa.in.gov.br/imprensa/jsp/visualiza/index.jsp?data $=10 / 02 / 2020 \&$ jornal=515\&pagina $=89 \&$ totalArquivos $=1$ 89. Acesso 23 de set. 2020.
} 
Nesta perspectiva pedagógica, a nova legislação propõe a alteração substancial na organização curricular das licenciaturas, com vistas de moldar a formação dos novos docentes. Contudo, para a concretização da formação docente preconizada, a Resolução 2/2019 vai determinar, primeiramente, a consonância da nova organização curricular dos cursos de licenciatura com as aprendizagens prescritas no interior/conteúdo da BNCC. Dentre os princípios norteadores elencados nas diretrizes, destaca-se: a centralidade da prática no processo formativo; o incentivo a efetivação do compromisso com a flexibilização curricular e a construção dos itinerários formativos, bases centrais da nova proposta curricular da BNCC; a avaliação dos cursos por instrumentos específicos que considerem a matriz de competências preconizadas pela PNPF, além das avaliações educacionais e pesquisas científicas (BRASIL, 2020).

Assim, no cenário idealizado para o próximo período da formação docente no país, designase a propositiva de organização curricular pautada em três grandes grupos de "conhecimentos" a serem contemplados durante o percurso formativo mínimo de 3200 horas, distribuídos em:

I - Grupo I: 800 (oitocentas) horas, para a base comum que compreende os conhecimentos científicos, educacionais e pedagógicos e fundamentam a educação e suas articulações com os sistemas, as escolas e as práticas educacionais.

II - Grupo II: 1.600 (mil e seiscentas) horas, para a aprendizagem dos conteúdos específicos das áreas, componentes, unidades temáticas e objetos de conhecimento da BNCC, e para o domínio pedagógico desses conteúdos.

III - Grupo III: 800 (oitocentas) horas, prática pedagógica, assim distribuídas:

a) 400 (quatrocentas) horas para o estágio supervisionado, em situação real de trabalho em escola, segundo o Projeto Pedagógico do Curso (PPC) da instituição formadora; e

b) 400 (quatrocentas) horas para a prática dos componentes curriculares dos Grupos I e II, distribuídas ao longo do curso, desde o seu início, segundo o PPC da instituição formadora. (BRASIL, 2020, p. 88).

Referente ao grupo III, destinado à prática pedagógica durante o percurso formativo, é que as diretrizes projetam a articulação dos conhecimentos absorvidos (grupo I e II) pelos futuros professores aplicando-os na prática cotidiana dos ambientes de ensino. Para tanto, a mesma sugere ao processo formativo, a inserção do licenciando no ambiente escolar, partindo, inicialmente, da familiarização da atividade docente, até finalizar seu percurso de prática pedagógica no estágio supervisionado. Além disso, a normativa define como modelo de registro de tais experiências e, possivelmente a avaliação do aluno-professor, o portfólio como meio/instrumento de evidenciar as aprendizagens obtidas e requeridas para o exercício da docência (planejamento, avaliação, conhecimento do conteúdo) (BRASIL, 2020).

Todavia, salientamos que esse processo de inserção, experimentação e sistematização preconizado pela nova legislação, assemelha-se em diversos pontos com a proposta elencadas nos 
editais do PRP. Na peculiaridade do edital 6/2018, o mesmo previa um total de 440 horas de atividades, sendo destas 60 horas destinadas à ambientação na escola; 320 horas de imersão (100 de regência), e 60 horas destinadas à elaboração de relatório final, avaliação e socialização de atividades (CAPES, 2018). Já no edital 1/2020, apresenta como carga horária do programa um total de 414 horas, organizadas em três módulos, divididos em 138 horas cada. Nesse universo, 86 horas se destinam a preparação da equipe, estudo sobre os conteúdos e metodologias de ensino, ambientação na escola, observação semiestruturada em sala de aula, elaboração de relatório do residente e avaliação da experiência; 12 horas de elaboração de planos de aula; e 40 horas de regência com acompanhamento do preceptor (CAPES, 2020).

Dessa perspectiva, constatamos um imbricamento/convergência nas propositivas que compõem a nova PNFP. Entre os pontos que poderíamos elencar estão o direcionamento, tanto da formação nas licenciaturas, como na proposta norteadora do PRP, em relação a BNCC, seus conteúdos, sua organização e seus princípios pedagógicos. Outra similaridade está na oferta quantitativa das cargas horárias das vivências/práticas docentes durante o processo formativo (400 horas de estágio curricular e 414 horas no PRP). Por fim, a congruência/correspondência dos objetivos preconizados pelo PRP e a nova proposta de formação para os cursos de licenciatura.

Apresentado os principais pontos encontrados nos documentos oficiais, tendo a última normativa (diretrizes curriculares nacionais para as licenciaturas) como objeto de análise e que objetiva balizar o reordenamento dos processos formativos dos futuros professores da educação básica e o conteúdo proposto/desenvolvido pelo PRP, compreendemos que tal viés empregado se destina apenas a atualizar a formação docente a nova realidade socioeconômica, caracterizada pela globalização e uso intensivo dos meios tecnológicos e que possibilitaram a intensificação e dinamização das relações sociais e econômicas da contemporaneidade.

Partindo dessa constatação anterior, a partir de agora, nos preocuparemos em construir o debate com diferentes autores, no sentido de consubstanciar nossas impressões com as reflexões/problematizações fornecidas em diferentes estudos, que possuem como enfoque a temática da orientação/perspectiva objetivada pela atual PNFP e, sua respectiva conexão com o PRP.

\section{OS RUMOS DA FORMAÇÃO DOCENTE NA CONTEMPORANEIDADE}

Com vistas a contemplar o objetivo traçado anteriormente, agora, discorremos teoricamente sobre a PNFP do recente período, na intenção de interagir com diferentes intelectuais da área educacional sobre tal temática. Tendo isso em mente, a formação de professores ganhou 
notoriedade não só pelo número elevado de autores que se dedicam em debater/discutir sobre o referido campo, mas também recebeu maior visualização através das políticas públicas advindas de sucessivas reformas educacionais implementadas em um curto período de tempo.

Nessa perspectiva, Souza, Souza e Aragão (2020), utilizando do pensamento de Ball (1994), observa que uma política educacional não se gesta de forma neutra no contexto social, intentando alterar/influenciar os propósitos sociais da educação. $\mathrm{Na}$ mesma tocada, segundo os autores, percebe-se uma disputa nos rumos formativos tanto dos estudantes do ensino básico, como dos profissionais dessa área, materializados pela grande relevância/presença de entidades privadas como, por exemplo, o Movimento Pela Base Nacional Comum, no processo de construção e desenvolvimento da BNCC no país.

Como desdobramentos da implementação da BNCC no universo educacional brasileiro, Souza, Souza e Aragão (2020, p. 417) aponta que, a Resolução CNE/CP nº 02/2015, sofreu com constantes mudanças desde o ano 2017 "em virtude das necessidades de adequação dos currículos da educação básica frente às orientações da BNCC e seu conjunto de aprendizagem", bem como, mais recentemente a Resolução $\mathrm{CNE} / \mathrm{CP} \mathrm{n}^{0}$ 02/2019, que visa assegurar à formação inicial dos professores a adequação priorizada pelas orientações encontradas na BNCC (SOUZA; SOUZA; ARAGÃO 2020).

Já para D’Avíla (2020), a formação estruturada a partir da listagem de competências a serem apropriadas pelos docentes, pode se configurar em uma reedição da psicologia comportamentalista (Behaviorista) criada nos Estados Unidos e, posteriormente importada ao Brasil, durante a ditadura militar, marcada pelo caráter tecnocrático/tecnicista. Para tanto, a autora salienta que a execução de tal perspectiva, demandará reverberações ideológicas e formativas, já que, desta normativa, se promoverá um "efeito cascata", abrangendo desde os docentes universitários, passando pelos educadores do ensino básico, findando nos alunos das redes básicas do país.

Freitas (2018), ao analisar o fenômeno da educacional no atual período, afirma que a educação tem sido vista - pelo empresariado - como um serviço a ser adquirido, e não como um direito social, devendo inclusive ser afastada do Estado para fins privativos de suas atividades. $\mathrm{O}$ autor, ainda reitera que:

[...] Do ponto de vista ideológico, a privatização também propicia um maior controle político do aparato escolar, agora visto como "empresa", aliado à padronização promovida pelas bases nacionais comuns curriculares e pela ação do movimento "escola sem partido", este último, uma braço político da "nova" direita na escola.

No campo técnico, a reforma permite o alinhamento da escola às necessidades dos novos processos produtivos, coordenado pela OCDE e agências internacionais, visando a inserção das cadeias produtivas nacionais na lógica das cadeias 
internacionais, o que exige um alinhamento com as necessidades da Revolução Industrial 4.0 e as reformas que ela demanda. (FREITAS, 2018, p. 29).

Em decorrência dessa lógica de submissão, das novas políticas em relação ao modelo idealizado a partir da promulgação da BNCC no contexto educacional que, Guedes (2020) declara a sua percepção em relação à política de formação docente ${ }^{8}$ estar intrinsecamente atrelada a qualidade da educação básica, de caráter neoliberal, focado no controle do que será e como será ensinado e aprendido, em depreciação a uma qualidade social, historicamente, reivindicada pela sociedade. Ainda, segundo a autora, é nesse conjunto de normativos provenientes do aparato estatal que surge a Proposta de Base Nacional Comum para Formação de Professores (BNCFP) - proposta preliminar lançada em 2018 - que tramitou durante um ano no Conselho Nacional de Educação, até ser aprovada a Resolução 2/2019, que recebeu alterações em seu conteúdo normativo e, que prioriza a formação docente:

[...] baseada na pedagogia das competências, tão fortemente defendida neste marco regulatório, amálgama uma visão restrita e instrumental de docência, em detrimento de uma concepção formativa que articula indissociavelmente a teoria $\mathrm{e}$ a prática, dentro de uma visão sócio-histórica, emancipadora e inclusiva (GUEDES, 2020, p. 96-97).

Integrada a um sistema de políticas públicas educacionais, a BNCFP, expõe-se o viés de alinhamento e padronização de políticas e ações, a qual pode ocasionar consequências extensas e com vasta tendência homogeneizadora no campo da formação, utilizando assim, ferramentas de controle, como apontada em um de seus textos:

Referência nacional para a formulação dos currículos dos sistemas e das redes escolares dos Estados, do Distrito Federal e dos Municípios e das propostas pedagógicas das instituições escolares, a BNCC integra a política nacional da Educação Básica e vai contribuir para o alinhamento de outras políticas e ações, em âmbito federal, estadual e municipal, referentes à formação de professores, à avaliação, à elaboração de conteúdos educacionais e aos critérios para a oferta de infraestrutura adequada para o pleno desenvolvimento da educação. (BRASIL, 2018a, p. 8).

Nesse sentido, e voltada às universidades, qual será o grau de liberdade dos cursos de ensino superior terão na elaboração e implementação de seu currículo, a partir do caráter apresentado nas normativas legais? Assim, o sentido, a ação e aquilo que pensamos, discutimos, refletimos e defendemos no interior dos cursos de formação de professores, não possuem implicações diretas no processo de implementação de tais políticas. Do mesmo modo, Souza, Bosco e Oliveira (2020) nos

\footnotetext{
${ }^{8}$ A autora destaca em sua análise sobre a política de formação docente, o Plano Nacional de Educação (2014-2024) instituído pela Lei 13.005/2014, bem como ao reconstruir o processo histórico recente das políticas educacionais, a autora salienta a relevância das normativas como a Lei 13,415 (Novo Ensino Médio), a BNCC e a Base da Educação Básica (Resolução CNE/CP 2/2017) no processo de regulamentar/moldar a formação de professores no país.
} 
atentam sobre políticas e os objetivos de programas como o PRP, implementados sem uma ampla discussão na comunidade educacional e acadêmica, sustentados na defesa da adequação da formação inicial a BNCC, além de dispor em seu conteúdo, um caráter propositivo pragmático e acentuar a discussão da dicotomia teoria-prática, discurso muito utilizado pelos organismos internacionais que se preocupam, a partir da visão dos autores, na "depreciação das instituições formadoras e desloca o problema da questão docente das condições de trabalho para a formação" (SOUZA; BOSCO; OLIVEIRA, 2020 p. 139).

$\mathrm{Na}$ tentativa de considerar que a qualidade da formação de professores é o aspecto mais importante referente ao desempenho dos alunos da educação básica, a BNCFP, emprega em seu discurso, a responsabilização absurda e irresponsavelmente dos docentes pelo desempenho dos alunos (RODRIGUES; PEREIRA; MOHR, 2020). Como apontada mais uma vez em seu texto: a BNCC deverá ser daqui em diante, uma referência para a formação inicial e continuada dos professores. Abre-se assim uma janela de oportunidade para debater alguns dos entraves e dar qualidade à formação do professor brasileiro (CAPES, 2018).

Já no que se refere à relação teoria e prática e, por conseguinte, no discurso empregado pelas autoridades governamentais na exposição e na midiatização das novas políticas, balizadas constantemente na preocupação de combater o excesso de teorizações/teorias pedagógicas que D’Avila (2020) defende a percepção do uso desenfreado do viés praticista na formação, por meio da minimização das teorizações pedagógicas/didáticas, cabendo ao processo de ensino, à luz da teoria das competências, apenas o conhecimento das práticas de ensino pretensamente isentas de ideologias. Ou seja, concretiza uma visão educacional aplicacionista, balizada na conquista das competências necessárias à docência, a partir do exercício prático nos estágios, ou ainda, em nosso ver em programas que compõem a PNFP como o PRP e o PIBID.

É nesse contexto que problematizamos a ideia de formar professores, a partir do PRP ligada a BNCC, pois como apresentado anteriormente, este tipo de formação desconsidera totalmente o intuito de constituir/construir docentes críticos e superadores das contradições da realidade educacional. O surgimento de "novas" políticas voltadas para o campo da formação de professores, não têm apresentado transformações concretas em suas estruturas, bem como, entre suas intenções, o que de fato acaba depreciando a formação destes indivíduos. Assim, retomamos o pensamento de Mézáros (2010), onde na atual condição sócia estrutural, apenas mudanças menores podem ser realizadas nas engrenagens que o sustentam, dentre essas, o sistema educacional e todos os demais procedimentos que circunstanciam sua prática social. 


\section{AS REPERCUSSÕES NA ESPECIFICIDADE DO ENSINO DA EDUCAÇÃO FÍSICA}

Na materialidade da formação em EF, a nova DCNEF (Resolução 06/2018), desdobramento das novas normativas do cenário educacional, impõe à área da EF a perpetuação de diferentes obstáculos para o avanço da qualificação dos futuros professores. Neste contexto, Ventura e Anes (2020) sinalizam à intensa influência/atuação do Conselho Federal de Educação Física (CONFEF) no interior do Conselho Nacional de Educação $(\mathrm{CNE})^{9}$ e, por conseguinte, no conteúdo recentes das normativas.

Primeiramente, a redação da DCNEF, institui algumas mudanças na formação em EF, já que divide o percurso formativo em duas etapas (comum e específica), cada uma delas com carga horária referencial de 1600 horas. Do mesmo modo que reafirma a posição de continuidade da fragmentação da área em licenciatura e bacharelado (BRASIL, 2018b).

Para Frizzo (2010), a atual fase da formação em EF está pautada nos modismos e nas sucessivas necessidades do mercado de trabalho que, em última instância, significam apoiar-se em um projeto histórico que esgotou as possibilidades de humanização, sobrevivendo à custa dos efeitos cada vez mais catastróficos e perversos sobre a população, em prol da proteção dos interesses econômicos.

Além disso, a divisão do curso, também, materializa o fracionamento do acesso ao conhecimento da cultura corporal. Nesse meio, Taffarel (2012), ao elaborar a crítica sobre essa divisão, situa que o intuito desses "rompimentos" foi para desregulamentar o trabalho por meio do ajuste especializado, tornando-se assim, um mecanismo que fragiliza o trabalhador pelas vias do esvaziamento teórico e pela delimitação nos campos de trabalho.

Corroborando, Quelhas e Nozaki (2006) sintetizam que esse processo de fragmentação da área efetiva duas principais resultantes no campo da EF: a) a cisão da classe de trabalhadores da área, os assalariados do magistério (licenciatura) e os autônomos, liberais e empreendedores (bacharelado); b) descaracterização epistemológica da área, posto que o objeto dela seja a prática docente independente do espaço profissional.

É a partir desta cisão que, atualmente, a área da EF está estruturada em dois campos distintos de atuação: o campo escolar e o não escolar. Essa divisão caracteriza fortemente a ideia de

\footnotetext{
${ }^{9}$ Frizzo (2010) aponta que historicamente o CONFEF atuou intensamente na elaboração de diferentes normativas com vistas a atender aos seus interesses corporativos, com enfoque especial na criação dos cursos de bacharelado em EF, já que não cabe aos conselhos profissionais ingerir sobre a atuação dos licenciados (incumbência do conselho nacional de educação) nos diferentes campos de trabalho, porém ao criar o bacharelado o referido conselho passa a ter o controle e a fiscalização dos professores que laboram nos campos não escolares.
} 
atender as demandas do mercado de trabalho, onde constantemente os profissionais da área necessitam adaptarem-se as constantes mudanças do mercado e, consequentemente, esse cenário leva-os a se inserir num mercado de trabalho cada vez mais precário e instável.

Já o segundo aspecto (descaracterização epistemológica), constatado por Ventura e Anes (2020) na redação da DCNEF (motricidade humana ou movimento humano; cultura do movimento corporal) nos remete a formação voltada ao mercado de trabalho contemporâneo, representando a negação dos acúmulos obtidos na produção acadêmica no universo da $\mathrm{EF}$ e, que, por consequência tem levado a sucessivos retrocessos nas políticas de formação. Por esse ângulo, Santos Júnior, Rodrigues e Lavoura (2020) afirma que estamos presenciando uma avalanche de regressões no campo educacional, onde se esvazia o debate em torno das recentes normativas e operacionaliza-se uma profunda mudança na direção política da formação em EF.

Contudo, essa descaracterização epistemológica, desconsidera a essência do trabalho desenvolvido pelos professores da área. Essa formação fragmentada está imbricada, em última instância, na própria divisão do trabalho, elemento fundante do sistema capitalista que, prioriza em suas normativas/proposições uma formação restrita, com viés unilateral, voltada as demandas das cadeias produtivas, em detrimento do desenvolvimento humano na sua integralidade, ou ainda, no sentido da unilateralidade defendida por importante intelectuais da área (NOZAKI, 2017).

Seguindo por esse raciocínio, entendemos que a formação em EF e a posteriori ocupação laboral, deve partir da vasta gama da produção do conhecimento, bem como, das intervenções realizadas pelos diferentes sujeitos na realidade concreta. Assim, concordamos com o pensamento de Nozaki (2017) onde defende que as formações (Pedagogia, EF) que a prática pedagógica é a expressão da intervenção concreta, ela deve ser o elemento de formação central, o que descredencia a necessidade de existir a fragmentação no interior da área, pois o professor que atua na escola ou fora desse ambiente (clubes, academias, clínicas, etc.), estão submetidas a mesma forma de exploração de sua força produtiva, bem como à precarização contemporânea do mundo do trabalho, que se desdobra na área nos modismos e na ilusão da necessidade de diferentes bacharelados para contemplar a existência dos diversos campos de trabalho e dos respectivos conhecimentos exigidos por essas particularidades.

Assim, defendemos que a formação em EF, tendo a prática pedagógica como base da identidade da área e, que se ocupa no trato pedagógico do objeto de estudo, a saber, a Cultura Corporal, tendo por objetivo desenvolver uma reflexão sobre o acervo de formas de representação do mundo, historicamente produzidas e exteriorizadas pela expressão corporal em suas diferentes manifestações (jogos, dança, lutas, exercícios ginásticos, malabarismo, esporte, entre outros) que podem ser compreendidos como retrato simbólico de realidades vividas pelos homens, 
historicamente criadas e desenvolvidas culturalmente na contemporaneidade (COLETIVO DE AUTORES, 2012).

\section{CONSIDERAÇÕES PRELIMINARES}

Como discorrido, o campo educacional, em específico, a área da formação docente, vem sistematicamente sendo alvo de intensas mudanças, oriundas da conjuntura política contemporânea, onde as alterações na formação docente são colocadas como essenciais para o próximo período. Contudo, é notório que essas modificações e implementações no cenário de formação de professores, estão marcadas pelas mudanças e exigências do mercado de trabalho contemporâneo, compreendendo assim, sua lógica de empregabilidade e de flexibilidade inerente aos novos processos produtivos.

Nesse sentido, é visível e, praticamente impossível, desvincular as políticas educacionais do sistema econômico e social, pois ambos são desenvolvidos para fins semelhantes e juntos tem contribuído significativamente para aumentar as desigualdades sociais de grande parte da população, ou seja, na lógica da economia, propõe-se o mínimo de qualidade para e com processo educacional, para que assim evite problemas políticos estruturais.

Dentro dessa perspectiva atual, o processo educacional tem sido colocado como serviço a ser adquirido, retirando-o como um direito social duramente conquistado. Nesta perspectiva, tem se apresentado um aumento de influências (setores privados) nas recentes normativas do ambiente educacional, como no exemplo da BNCC, onde a estrutura e as orientações do documento norteador atenderam diferentes pontos desses setores e que interligam diretamente o perfil do novo educando para o novo cenário socioeconômico e, por conseguinte, intenta na necessidade de preparar/formar os futuros professores à luz das diretrizes contidas na BNCC através da execução da nova Resolução CNE/CP n 02/2019 construída de maneira verticalizada e sem amplo debate de seu conteúdo.

Contudo, no campo específico da Educação Física, também se percebe mudanças e ressignificações impostas, em especial pela DCN-EF, na tentativa de adequá-la aos novos rumos formativos. Como apontado ao longo do texto, essas alterações objetivam forjar um perfil de sujeito capaz de se adequar a inúmeras situações profissionais, não interessando qualificação integral desses profissionais, tornando o processo formativo em Educação Física, precário, superficial e compatível com a dinamicidade/rotatividade do presente mercado de trabalho.

Ao processo educacional como um todo - educação básica e formação docente -, têm sido imposto ações que desconsideram o conhecimento epistemológico e contrapõe a constituição de 
sujeitos críticos para com a realidade social. Desse modo, se percebe uma perda de sentidos e significados ao processo de ensino e de aprendizagem dos mesmos, descaracterizando o papel social da educação, como também, na função política realizada na especificidade de socializar o conhecimento historicamente sistematizado pelas diferentes áreas do saber humano (SAVIANI, 2012).

\section{REFERÊNCIAS}

AGUIAR, Márcia Ângela Silva. Relato da resistência à instituição da BNCC pelo Conselho Nacional de Educação mediante pedido de vista e declarações de votos. In: AGUIAR, Márcia, Ângela. Silva; DOURADO, Luiz Fernando. (Orgs.). A BNCC na contramão do PNE 2014-2024: avaliação e perspectivas. [Livro Eletrônico]. Recife: ANPAE, 2018. Disponível em: https://www.anpae.org.br/BibliotecaVirtual/4-Publicacoes/BNCC-VERSAO-FINAL.pdf. Acesso em: 29 set. 2020.

BARONE, Rosa Elisa Mirra. Educação e políticas públicas: questões para o debate. Boletim técnico do SENAC, Rio de Janeiro: v. 26, n. 3, p. 3-18, set./dez.,2000.

BRASIL. Resolução CNE/CP N 2/2019. Define as Diretrizes Curriculares Nacionais para a Formação Inicial de Professores para a Educação Básica e institui a Base Nacional Comum para a Formação Inicial de Professores da Educação Básica (BNC-Formação). Diário Oficial da União: seção 1, Brasília, DF, ano 157, n. 28, p. 87-90, 10 fev. 2020. Disponível em:

https://pesquisa.in.gov.br/imprensa/jsp/visualiza/index.jsp?data=10/02/2020\&jornal=515\&pagina=89\&totalArquivos $=1$ 으. Acesso em: 27 set. 2020.

BRASIL. Ministério da Educação. Base Nacional Comum Curricular. Educação é Base. MEC: Brasília, 2018a. Disponível em: http://basenacionalcomum.mec.gov.br/abase/. Acesso em: 09 ago. 2020.

BRASIL. Ministério da Educação. Proposta para Base Nacional Comum da Formação de Professores da Educação Básica. 2018.

BRASIL. Ministério da Educação. Resolução CNE/CES No 6/2018. Institui Diretrizes Curriculares Nacionais dos Cursos de Graduação em Educação Física e dá outras providências. MEC: Brasília, 2018b. Disponível em: http://www.in.gov.br/materia/-/asset publisher/Kujrw0TZC2Mb/content/id/55877795/do1-2018-12-19-resolucao-n-6de-18-de-dezembro-de-2018-55877683. Acesso em: 30 ago. 2020.

COLETIVO DE AUTORES. Metodologia do ensino da educação física. 2a ed. São Paulo: Cortez. 200p. 2012.

COORDENAÇÃO DE APERFEIÇOAMENTO DE PESSOAL DE NÍVEL SUPERIOR. Programa de Residência Pedagógica, Brasília, DF, 2018. Disponível em: https://www.gov.br/capes/pt-br/centrais-de-conteudo/01032018-edital6-2018-residencia-pedagogica-pdf/view. Acesso em: 27 de set. 2020.

COORDENAÇÃO DE APERFEIÇOAMENTO DE PESSOAL DE NÍVEL SUPERIOR. Programa de Residência Pedagógica, Brasília, DF, 2020. Disponível em: https://www.gov.br/capes/pt-br/centrais-de-conteudo/06012020-edital1-2020-residencia-pedagogica-pdf/view. Acesso em: 27 de set. 2020.

COSTA, Carolina Caporal Dantas; GONÇALVES, Suzane Rocha Vieira. A residência pedagógica e o pragmatismo na formação docente. In.: Encontro Textos e Contextos da Docência. Anais Eletrônicos ISBN: 978-85-7566-571-8. Rio Grande, RS. Universidade Federal do Rio Grande - FURG. 2019. Disponível em: https://textosecontextosdadocencia.furg.br/images/doc/ANAIS TEXTOS E CONTEXTOS 2019.pdf. Acesso em: 27 set. 2020.

D'AVILA, Cristina. A didática nas Diretrizes Curriculares Nacionais e Base Nacional Comum para a Formação de Professores da Educação Básica: impasses, desafios e resistências. Revista Cocar. Edição Especial, n. 8, jan./abr., p. 86-101, 2020. 
FREITAS, Luis Carlos. A reforma educacional da educação: nova direita, velhas ideias. 1. ed. São Paulo: Expressão Popular, 2018.

FRIZZO, Giovanni. Divisão da formação em educação física: "crônica de uma morte anunciada" Germinal: Marxismo e Educação em Debate, Londrina, v. 2, n. 2, p. 163-173; ago. 2010.

GIL, Antônio. Métodos e técnicas de pesquisa social. 6. ed. São Paulo: Atlas, 2008.

GUEDES, Maria. Q. Política de formação docente: as novas diretrizes e a base nacional comum instituídas. Sul-Sul -

Revista De Ciências Humanas e Sociais, v. 1, n. 1, p. 82-103, 2020.

MÉZÁROS, István. A educação para além do capital. 1 ed. São Paulo: Boitempo, 2010.

NOZAKI, Hajime Takeuchi. Diretrizes curriculares, formação unificada e campos políticos na educação física brasileira: em defesa do marxismo. Germinal: Marxismo e Educação em Debate, Salvador, v. 9, n. 1, p. 72-85, abr. 2017.

PORTELINHA, Ângela Maria Silveira; NEZ, Egeslaine; BORDIGNON, Luciane Spanhol. Política de formação de professores: reflexões sobre o pibib e o programa residência pedagógicas. Interfaces Científicas - Educação, Aracaju, v. 9, n. 1, p. 29-42, 2020. Disponível em: https://periodicos.set.edu.br/educacao/article/view/8736/3981. Acesso em: 27 set. 2020 .

QUELHAS, Álvaro Azeredo; NOZAKI, Hajime. Takeuchi. A formação do professor de educação física e as novas diretrizes curriculares frente aos avanços do capital. Motrivivência, Florianópolis, ano 18, n. 26, p. 69-87, jun. 2006.

RODRIGUES, Larissa Zancan; PEREIRA, Beatriz; MOHR, Adriana. O Documento "Proposta para Base Nacional Comum da Formação de Professores da Educação Básica” (BNCFP): Dez Razões para Temer e Contestar a BNCFP. Revista brasileira de pesquisa em educação em ciências, v. 20, p. 1-39, 2020. Disponível em: https://periodicos.ufmg.br/index.php/rbpec/article/view/16205/15250. Acesso em: 27 set. 2020.

SANTOS JÚNIOR, Claúdio de Lira; RODRIGUES, Raquel Cruz Freire; LAVOURA, Tiago Nicola. Formação de professores de educação física: velhos problemas, novas lutas. In. SOARES, Marta Genú; ATHAYDE, Pedro; LARA, Larissa (Orgs.). Formação profissional e mundo do trabalho. Natal, RN : EDUFRN, 2020.

SAVIANI, Demerval. Escola e Democracia. 42 ed. Campinas, SP: Autores Associados. (Coleção polêmicas do nosso tempo; 5). 2012.

SHIROMA, Eneida Oto; MORAES, Maria Célia Marcondes; EVANGELISTA, Olinda. Política educacional. Rio de Janeiro: DP\&A Editora, 2002.

SILVA, Katia Augusta Curado Pinheiro; CRUZ, Shirleide Pereira. A Residência Pedagógica na formação de professores: história, hegemonia e resistências. Momento: diálogos em educação, v. 27, n. 2, p. 227-247, mai./ago, 2018. Disponível em: https://periodicos.furg.br/momento/article/view/8062/5352. Acesso em 30 jun. 2020.

SOUZA, Juliana Fátima; BOSCO, Claudia Starling; OLIVEIRA, Dalila Andrade. Políticas de formação e a profissionalização docente no Brasil: o pibid e a residência pedagógica. Formação em Movimento, v.2, n.3. p.126-145, jan./jun.2020. Disponível em: http://costalima.ufrrj.br/index.php/FORMOV/article/view/581/863. Acesso em: 27 set. 2020 .

SOUZA, Sawana Araújo Lopez; SOUZA, Maraiane Pinto; ARAGÃO, Wilson Honorato. Dialogando sobre a bncc, o currículo e a sua interferência para a formação de professores. Revista on line de Política e Gestão Educacional, Araraquara, v. 24, n. 2, p. 412-424, mai/ago., 2020. Disponível em:

https://periodicos.fclar.unesp.br/rpge/article/view/13536/9080. Acesso em: 27 set. 2020.

TAFFAREL, Celi Neliza Zulke. A formação de professores de Educação Física e a licenciatura ampliada. In: SEMANA DE EDUCAÇÃO FÍSICA/UFMS, 17; JORNADA DE INICIAÇÃO CIENTÍFICA DO CURSO DE EDUCAÇÃO FÍSICA/UFMS, 4. 2012. Disponível em: https://repositorio.ufba.br/ri/handle/ri/18055. Acesso em: 12 jan. 2021.

VENTURA, Paulo Roberto Veloso; ANES; Rodrigo Roncato Marques. Formação profissional em educação física: dilemas, divergências e protagonismos das DCN atuais. In. SOARES, Marta Genú; ATHAYDE, Pedro; LARA, Larissa (Orgs.). Formação profissional e mundo do trabalho. Natal, RN: EDUFRN, 2020. 


\section{NOTAS DE AUTOR}

AGRADECIMENTOS - Não se aplica.

CONTRIBUIÇÃO DE AUTORIA - Não se aplica.

FINANCIAMENTO - Não se aplica.

CONSENTIMENTO DE USO DE IMAGEM - Não se aplica.

APROVAÇÃO DE COMITÊ DE ÉTICA EM PESQUISA - Não se aplica.

CONFLITO DE INTERESSES

Informamos que não há conflito de interesses nesse trabalho.

\section{LICENÇA DE USO}

Os autores cedem à Motrivivência - ISSN 2175-8042 os direitos exclusivos de primeira publicação, com o trabalho simultaneamente licenciado sob a Licença Creative Commons Attribution Non-Comercial ShareAlike (CC BY-NC SA) 4.0 International. Esta licença permite que terceiros remixem, adaptem e criem a partir do trabalho publicado, desde que para fins não comerciais, atribuindo o devido crédito de autoria e publicação inicial neste periódico desde que adotem a mesma licença, compartilhar igual. Os autores têm autorização para assumir contratos adicionais separadamente, para distribuição não exclusiva da versão do trabalho publicada neste periódico (ex.: publicar em repositório institucional, em site pessoal, publicar uma tradução, ou como capítulo de livro), com reconhecimento de autoria e publicação inicial neste periódico, desde que para fins não comerciais e compartilhar com a mesma licença.

\section{PUBLISHER}

Universidade Federal de Santa Catarina. Programa de Pós-Graduação em Educação Física. LaboMídia - Laboratório e Observatório da Mídia Esportiva. Publicado no Portal de Periódicos UFSC. As ideias expressadas neste artigo são de responsabilidade de seus autores, não representando, necessariamente, a opinião dos editores ou da universidade.

\section{EDITORES}

Mauricio Roberto da Silva, Giovani De Lorenzi Pires, Rogério Santos Pereira.

EDITOR DE SEÇÃO

Giovani De Lorenzi Pires

REVISÃO DO MANUSCRITO E METADADOS

João Caetano Prates Rocha; Keli Barreto.

\section{HISTÓRICO}

Recebido em: 03 de março de 2021.

Aprovado em: 27 de abril de 2021. 